\title{
Anti-oral Microbial Flavanes from Broussonetia papyrifera Under the Guidance of Bioassay
}

\author{
Chang-An Geng ${ }^{1,2} \cdot$ Meng-Hong Yan ${ }^{1,2} \cdot$ Xue-Mei Zhang ${ }^{1,2} \cdot$ Ji-Jun Chen ${ }^{1,2,3}$ (i)
}

Received: 26 November 2018 / Accepted: 6 January 2019 / Published online: 16 January 2019

(c) The Author(s) 2019

\begin{abstract}
A new flavane, bropapyriferol (1), and eleven known ones were isolated from the EtOAc part of Broussonetia papyrifera under the guidance of bioassay. The structure of compound 1 was determined by extensive $1 \mathrm{D}$ and $2 \mathrm{D}$ NMR, $[\alpha]_{\mathrm{D}}$ spectroscopic data and quantum computation. Daphnegiravan F (2) and 5,7,3',4'-tetrahydroxy-3-methoxy-8,5'-diprenylflavone (3) showed significantly anti-oral microbial activity against five Gram-positive strains and three Gram-negative strains in vitro. Especially, compound $\mathbf{3}$ was more potent in suppressing Actinomyces naeslundii and Porphyromonas gingivalis $(\mathrm{MIC}=1.95 \mathrm{ppm})$ than the positive control, triclosan.
\end{abstract}

\section{Graphical Abstract}
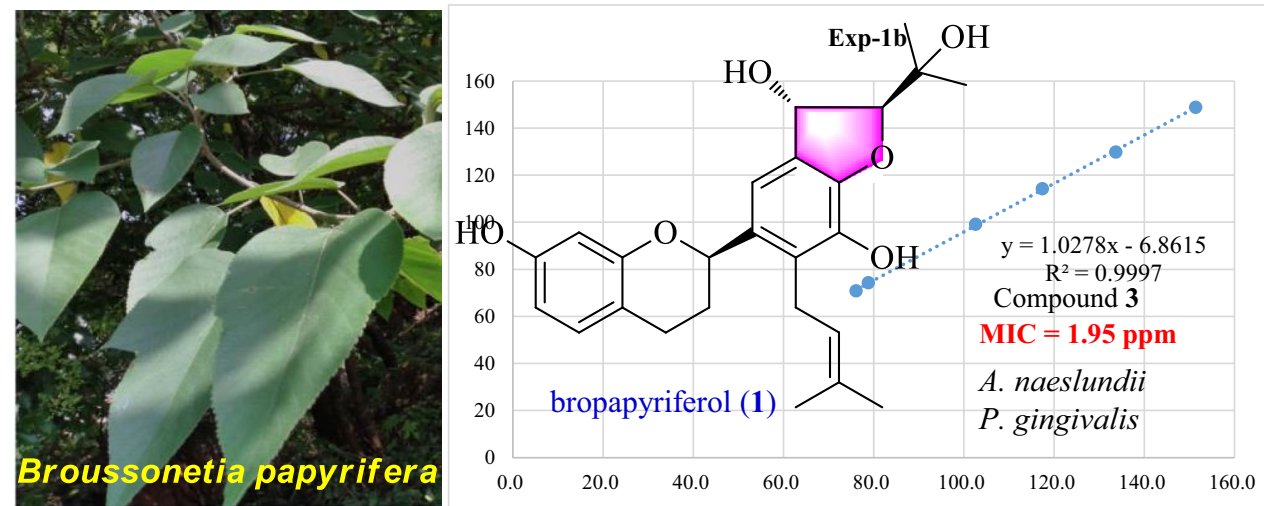

Keywords Bropapyriferol · Broussonetia papyrifera $\cdot$ Anti-oral microbial activity

Electronic supplementary material The online version of this article (doi:https://doi.org/10.1007/s13659-019-0197-y) contains supplementary material, which is available to authorized users.

Ji-Jun Chen

chenjj@mail.kib.ac.cn

1 State Key Laboratory of Phytochemistry and Plant Resources in West China, Kunming Institute of Botany, Chinese Academy of Sciences, 132\# Lanhei Road, Kunming 650201, Yunnan, People's Republic of China

2 Yunnan Key Laboratory of Natural Medicinal Chemistry, Kunming 650201, People's Republic of China

3 University of Chinese Academy of Sciences, Beijing 100049, People's Republic of China

\section{Introduction}

Broussonetia papyrifera, a deciduous broadleaf plant in the family Moraceae, is native to Asia, and mainly distributed in China, Japan, Vietnam and India. B. papyrifera also known as paper mulberry is a highly valued plant in China, whose leaves, roots, barks and fruits are used in traditional Chinese medicines (TCMs) for diuretic, anti-rheumatic, anti-bacterial, anti-inflammatory purposes. Its bark is a good source for papermaking and leaves are high quality feed. Now, this plant widely grows in Europe, the United States and Africa as introduced a species [1,2]. The main constituents of $B$. papyrifera are flavones, lignans, diterpenes and triterpenes 
[3-8]. In the previous investigation, three flavanes, kazinol B, 7,4'-dihydroxy-3'-prenylflavan and 3'-(3-methylbut-2enyl)-3',4',7-trihydroxyflavane, and one triterpene, oleanolic acid, from the cortex were revealed with anti-oral microbial activity [9]. In order to clarify the anti-oral microbial effects of B. papyrifera and the active constituents, the preliminary bioassay revealed that the EtOAc part showed increased activity comparing to the total extraction. Thus, detailed investigation was performed on the active EtOAc part and yielded one new flavane, bropapyriferol, and eleven known ones. Herein, we report their isolation, structural elucidation and anti-oral microbial activities.

\section{Results and Discussion}

\subsection{Structure Elucidation}

Compound 1 was assigned the molecular formula of $\mathrm{C}_{25} \mathrm{H}_{30} \mathrm{O}_{6}$ from the positive HRESIMS at $\mathrm{m} / z 449.1954$ $\left([\mathrm{M}+\mathrm{Na}]^{+}\right.$, calcd. for 449.1940), with 11 degrees of unsaturation. The IR absorptions at 3419, 1623, 1600, 1509 and $1463 \mathrm{~cm}^{-1}$ were indicative for the presence of hydroxy, double bond and phenyl groups. In the ${ }^{1} \mathrm{H}$ NMR spectrum, three ABX-coupling protons at $\delta_{\mathrm{H}} 7.10(\mathrm{~d}, J=8.2 \mathrm{~Hz}, \mathrm{H}-5)$, 6.87 (dd, $J=8.2,2.4 \mathrm{~Hz}, \mathrm{H}-6)$ and 6.93 (d, $J=2.4 \mathrm{~Hz}, \mathrm{H}-8$ ) suggested a 1,2,4-trisubstituted phenyl ring. In addition, one aromatic proton at $\delta_{\mathrm{H}} 7.20$ and four methyls at $\delta_{\mathrm{H}} 1.75$, $1.63,1.49$ and 1.41 , all in singlet, were obviously recognized. In the ${ }^{13} \mathrm{C}$ NMR spectrum, one methine $\left(\delta_{\mathrm{C}} 75.7\right)$ and two methylenes $\left(\delta_{\mathrm{C}} 30.7\right.$ and 25.8) were characteristic for a flavane skeleton when taking 12 aromatic carbons into consideration. One prenyl group was deduced from the methylene $\left(\delta_{\mathrm{H}} 3.83, \mathrm{~d}, J=6.6 \mathrm{~Hz} ; \delta_{\mathrm{C}} 25.4\right)$, tri-substituted double bond $\left(\delta_{\mathrm{H}} 5.49, \mathrm{t}, J=6.6 \mathrm{~Hz} ; \delta_{\mathrm{C}} 124.8\right.$ and 130.5$)$ and two tertiary methyls $\left(\delta_{\mathrm{H}} 1.75\right.$ and 1.63 , both s; $\delta_{\mathrm{C}} 18.0$ and 25.8$)$. From the above analyses, this compound was proposed to be a prenylated flavane [6].

The NMR data of $\mathbf{1}$ showed similarity with those of daphnegiravan F [10], and the main difference was that compound 1 had an addition 2-hydroxypropan-2-yl group (two methyls: $\delta_{\mathrm{H}} 1.41$ and $1.49, \delta_{\mathrm{C}} 26.4$ and 25.8 ; one oxygenated quaternary carbon: $\left.\delta_{\mathrm{C}} 70.8\right)$ and two methines $\left(\delta_{\mathrm{H}} 6.07\right.$ and $4.94, \delta_{\mathrm{C}} 74.3$ and 99.1) instead of a double bond (Table 1). Detailed analysis of the 2D NMR spectra well established its planar structure: the ${ }^{1} \mathrm{H}-{ }^{1} \mathrm{H}$ COSY correlation of $\mathrm{H}-5$ with $\mathrm{H}-6$, and HMBC correlations from $\mathrm{H}-6$ and $\mathrm{H}-8$ to C-4a, and from $\mathrm{H}-5$ to $\mathrm{C}-7$ verified a hydroxyl group at $\mathrm{C}-7$; the $\mathrm{HMBC}$ correlations from $\mathrm{H}-8^{\prime}$ to $\mathrm{C}-2^{\prime}$, and from $\mathrm{H}-7^{\prime}$ to $\mathrm{C}-1^{\prime}$ and $\mathrm{C}-3^{\prime}$ suggested the prenyl group at $\mathrm{C}-2^{\prime}$; the ${ }^{1} \mathrm{H}-{ }^{1} \mathrm{H}$ COSY correlation of $\mathrm{H}-12^{\prime}$ with $\mathrm{H}-13^{\prime}$, and $\mathrm{HMBC}$ correlations from $\mathrm{H}-15^{\prime}$ and $\mathrm{H}-16^{\prime}$ to $\mathrm{C}-13^{\prime}$ indicated a hydroxyl group at C-12' and 2-hydroxypropan-2-yl group at C-13' (Fig. 1).
Table $1{ }^{1} \mathrm{H}$ and ${ }^{13} \mathrm{C}$ NMR data of compound 1 in pyridine- $d_{5}(\delta$ in ppm, $J$ in $\mathrm{Hz}$ )

\begin{tabular}{llr}
\hline No. & ${ }^{1} \mathrm{H}$ NMR $(400 \mathrm{MHz})$ & ${ }^{13} \mathrm{C} \mathrm{NMR}$ \\
& & $(100 \mathrm{MHz})$ \\
\hline 2 & $5.42, \mathrm{brd}, 9.2$ & $75.7, \mathrm{~d}$ \\
3 & $2.13, \mathrm{~m}$ & $30.7, \mathrm{t}$ \\
& $2.02, \mathrm{~m}$ & \\
4 & $2.94, \mathrm{~m}$ & $25.8, \mathrm{t}$ \\
& $2.71, \mathrm{dd}, 15.7,2.9$ & \\
$4 \mathrm{a}$ & - & $113.1, \mathrm{~s}$ \\
5 & $7.10, \mathrm{~d}, 8.2$ & $130.8, \mathrm{~d}$ \\
6 & $6.87, \mathrm{dd}, 8.2,2.4$ & $109.3, \mathrm{~d}$ \\
7 & - & $158.4, \mathrm{~s}$ \\
8 & $6.93, \mathrm{~d}, 2.4$ & $104.3, \mathrm{~d}$ \\
$8 \mathrm{a}$ & - & $157.4, \mathrm{~s}$ \\
$1^{\prime}$ & - & $133.8, \mathrm{~s}$ \\
$2^{\prime}$ & - & $128.1, \mathrm{~s}$ \\
$3^{\prime}$ & - & $140.1, \mathrm{~s}$ \\
$4^{\prime}$ & - & $148.8, \mathrm{~s}$ \\
$5^{\prime}$ & - & $129.8, \mathrm{~s}$ \\
$6^{\prime}$ & 7.20, overlapped & $114.2, \mathrm{~d}$ \\
$7^{\prime}$ & $3.83, \mathrm{~d}, 6.6$ & $25.4, \mathrm{t}$ \\
$8^{\prime}$ & $5.49, \mathrm{t}, 6.6$ & $124.8, \mathrm{~d}$ \\
$9^{\prime}$ & - & $130.5, \mathrm{~s}$ \\
$10^{\prime}$ & $1.75, \mathrm{~s}$ & $18.0, \mathrm{q}$ \\
$11^{\prime}$ & $1.63, \mathrm{~s}$ & $25.8, \mathrm{q}$ \\
$12^{\prime}$ & $6.07, \mathrm{~d}, 4.4$ & $74.3, \mathrm{~d}$ \\
$13^{\prime}$ & $4.94, \mathrm{~d}, 4.4$ & $99.1, \mathrm{~d}$ \\
$14^{\prime}$ & - & $70.8, \mathrm{~s}$ \\
$15^{\prime}$ & $1.49, \mathrm{~s}$ & $26.4, \mathrm{q}$ \\
$16^{\prime}$ & & $25.8, \mathrm{q}$ \\
\hline & & \\
& &
\end{tabular}

The stereochemistry at $\mathrm{C}-12^{\prime}$ and $\mathrm{C}-13^{\prime}$ was deduced as trans-form by the coupling constant $\left(J_{\mathrm{H}-12^{\prime}, \mathrm{H}-13^{\prime}}=4.4 \mathrm{~Hz}\right)$ and comparing with that of 16-hydroxycudratrixanthone $\mathrm{Q}$ [11]. In order to determine the stereochemistry of $\mathbf{1}$, the two possible configurations, $2 S^{*}, 12^{\prime} S^{*}, 13^{\prime} S^{*}-1$ (1a) and $2 S^{*}, 12^{\prime} R^{*}, 13^{\prime} R^{*}-\mathbf{1}(\mathbf{1 b})$, were applied to quantum computation at the B3LYP/6-311+g(d,2p) level for the ${ }^{13} \mathrm{C}$ NMR data. As shown in Fig. 2, the calculated NMR data for $\mathbf{1 b}$ matched well with the experimented data, with the correlation coefficient $\left(R^{2}\right)$ of 0.9979 , when comparing with that of the calculated 1a. In addition, the correlation coefficient $\left(R^{2}\right)$ was up to 0.9997 when only the carbons $\left(\mathrm{C}-4^{\prime}, 5^{\prime}, 6^{\prime}\right.$, $12^{\prime}, 13^{\prime}$ and $14^{\prime}$ ) near $\mathrm{C}-12^{\prime}$ and $\mathrm{C}-13^{\prime}$ takes into consideration. The absolute stereochemistry was determined to be $2 R, 12^{\prime} S, 13^{\prime} S$ by the positive $[\alpha]_{\mathrm{D}}$ value which is consistent with the previous report and quantum calculation [12]. Thus, the structure of $\mathbf{1}$ was determined and named to be bropapyriferol.

The known compounds were determined as daphnegiravan F (2) [10], 
Fig. 1 Structure of 1 and the key 2D NMR correlations ( $\rightarrow$ $\mathrm{HMBC},{ }^{1} \mathrm{H}-{ }^{1} \mathrm{H}$ COSY)<smiles>CC(I)=CCc1c(C2CCc3ccc(O)cc3O2)cc2c(c1O)O[C@H](C(C)(O)Br)[C@@H]2O</smiles>

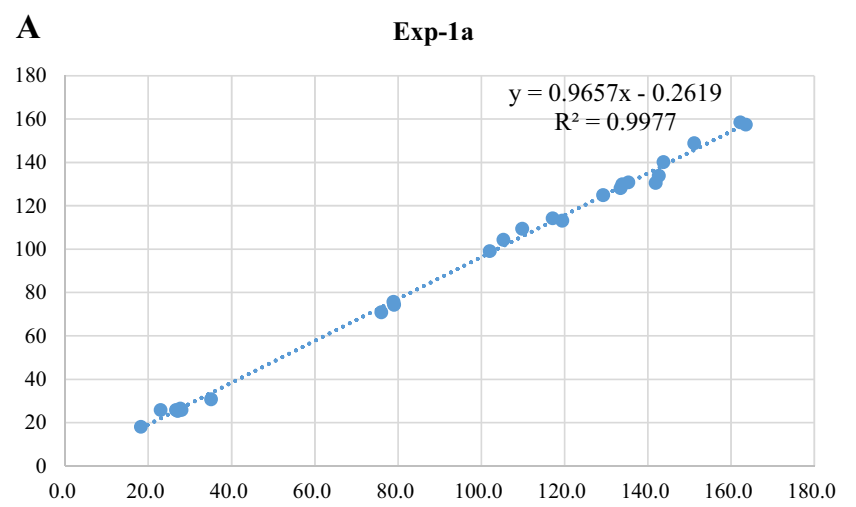

\section{C}

Exp-1a

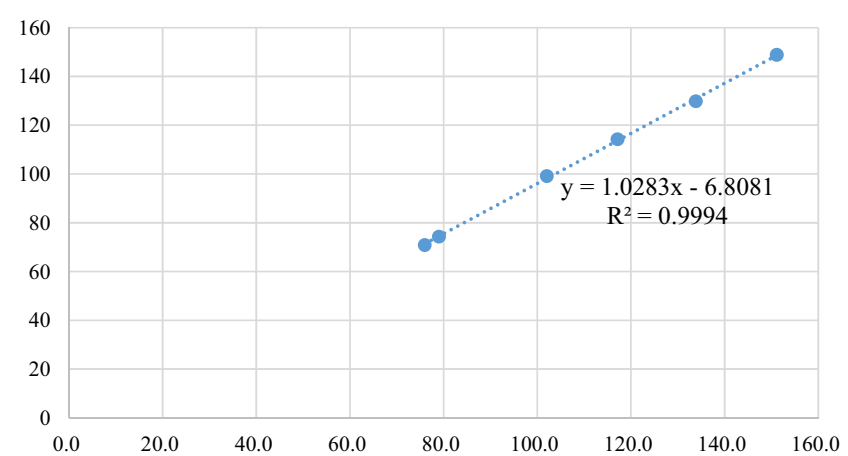

\section{B}

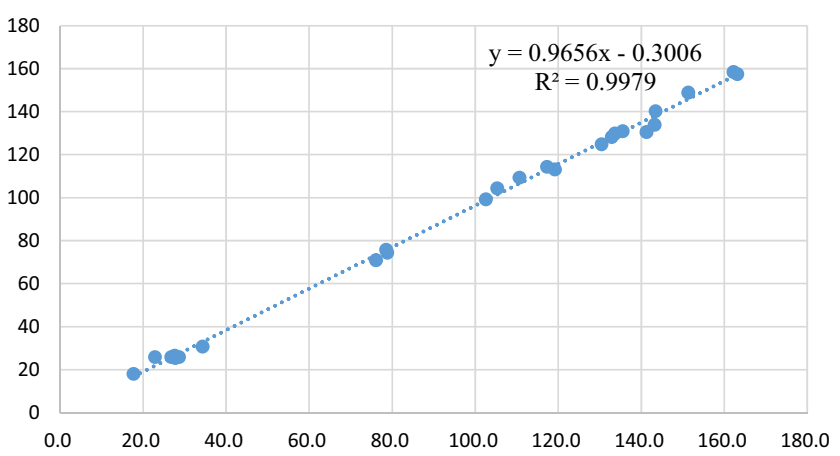

D

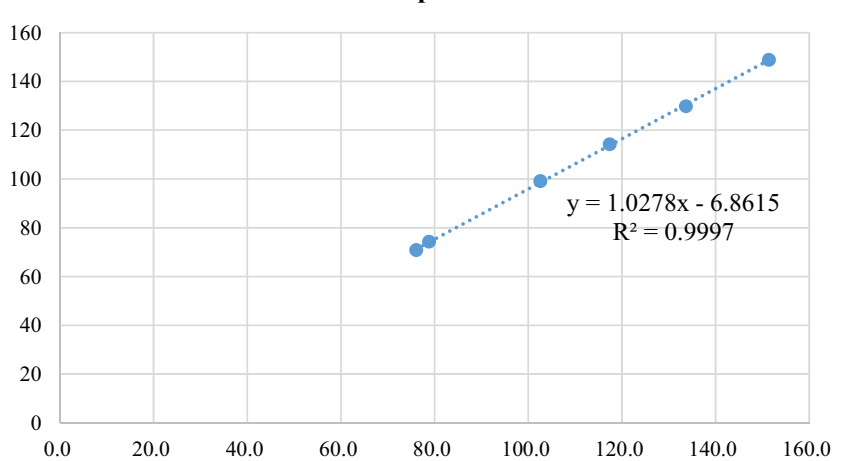

Fig. 2 The correlations between calculated and experimental ${ }^{13} \mathrm{C}$ NMR data for two possible configurations of $\mathbf{1}$ (1a and $\left.\mathbf{1 b}\right)$. All carbons (a and b) and only $\mathrm{C}^{-4} \mathbf{\prime}^{\prime}, 5^{\prime}, 6^{\prime}, 12^{\prime}, 13^{\prime}, 14^{\prime}$ (c and d) were considered

$5,7,3^{\prime}, 4^{\prime}$-tetrahydroxy-3-methoxy-8,5'-diprenylflavone (3) [13], broussoflavonol B (4) [14], broussonin A (5) [15], isoliquiritigenin (6) [16], uralenol (7) [17], broussoflavan A (8) [18], uralene (9) [19], uralenol-3-methylether (10) [19], abyssinone VII (11) [20] and 3,5,7,3',5'-pentahydroxyflavanone (12) [21] by comparing with the previous reports.

\subsection{Anti-oral Microbial Activity}

The total extraction and each fraction were assayed for the anti-oral microbial activity against two Gram-positive and two Gram-positive strains. As shown in Table 2, the total extraction showed activity against the four assayed
Table 2 Anti-oral microbial activity of fractions from B. papyrifera expressed as MIC (ppm)

\begin{tabular}{lllll}
\hline Fractions & A. viscosus & S. mutans & F. nucleatum & P. gingivalis \\
\hline Total extraction & 39 & 39 & 39 & 19.5 \\
PE part & $>1250$ & $>1250$ & $>1250$ & 39 \\
EtOAc part & 19.5 & 19.5 & 19.5 & 9.8 \\
n-Butanol part & 78.1 & 39 & 78.1 & 39 \\
Water part & $>1250$ & $>1250$ & $>1250$ & $>1250$ \\
Triclosan $^{c}$ & 3.9 & 3.9 & 7.8 & 7.8 \\
\hline
\end{tabular}


strains, $A$. viscosus, $S$. mutans, $F$. nucleatum and $P$. gingivalis with MIC values of 39, 39, 39 and $19.5 \mathrm{ppm}$, respectively. After extraction by different solvents, the EtOAc part showed the highest activity with MIC values of $19.5,19.5,19.5$ and $9.8 \mathrm{ppm}$; the $n$-butanol part exhibited slightly decreased activity with MIC values of 78.1, 39, 78.1 and $39 \mathrm{ppm}$; and the petroleum ether (PE) and water parts are inactive except for the PE part showing inhibition on $P$. gingivalis $(\mathrm{MIC}=39 \mathrm{ppm}$ ).

Compounds 1-12 were assayed for their anti-oral microbial activity against five Gram-positive strains ( $A$. naeslundii, A. viscosus, S. mutans, $S$. sanguinis and $S$. sorbrinus) and three Gram-negative strains (A. actinomycetemcomitans, $F$. nucleatum, $P$. gingivalis). As shown in Table 3, compound $\mathbf{2}$ exhibited significant activity against all the strains except for $S$. sorbrinus, with MIC values of $7.8,7.8,3.9,15.6,62.5,3.9,3.9$ and $7.8 \mathrm{ppm}$, which is comparable to the positive control, triclosan. Compound 3 could obviously inhibit five Gram-positive strains and one Gram-negative strain ( $P$. gingivalis), with MIC values between 1.95 and $15.6 \mathrm{ppm}$. For A. naeslundii and $P$. gingivalis, compound 3 showed an MIC value of $1.95 \mathrm{ppm}$, even higher than triclosan $(\mathrm{MIC}=3.9$ and $7.8 \mathrm{ppm}$, repectively). In addition, compound $\mathbf{1 0}$ also showed comparable inhibition with triclosan on two Gram-negative strains, F. nucleatum (MIC $=7.8 \mathrm{ppm}$ ) and $P$. gingivalis $(\mathrm{MIC}=7.8 \mathrm{ppm})$.

Table 3 Anti-oral microbial activity of compounds 1-12 expressed as MIC (ppm)

\section{Experimental}

\subsection{General Procedures}

Optical rotations were collected on a Jasco model 1020 polarimeter (Horiba, Tokyo, Japan). UV spectra were determined on a Shimadzu UV-2401A spectrophotometer (Shimadzu, Kyoto, Japan). IR (KBr) spectra were recorded on a BioRad FTS-135 spectrometer (Bio-Rad, Hercules, California, USA). 1D and 2D NMR spectra were recorded on a Bruker AM-400 NMR or DRX-500 spectrometer with TMS as the internal standard (Bruker, Bremerhaven, Germany). MS data were collected on a VG Auto Spec-3000 spectrometer (VG, Manchester, UK) and an API Qstar Pulsar hybrid Q-TOF mass spectrometer (AB-Sciex, Framingham, MA, USA).

\subsection{Plant Materials}

The plant materials of Broussonetia papyrifera (Linn.) L'Hér. ex Vent. were collected from Chongqing, China, in August 2009, and authenticated by Dr. Li-Gong Lei (Kunming Institute of Botany, CAS). A voucher specimen (No. 200908001) was deposited in the Laboratory of Antivirus and Natural Medicinal Chemistry, Kunming Institute of Botany, CAS.

\subsection{Extraction and Isolation}

The air-dried aerial part ( $5 \mathrm{~kg}$ ) of B. papyrifera was powdered and extracted with $\mathrm{EtOH}(90 \%)$ at room temperature

\begin{tabular}{|c|c|c|c|c|c|c|c|c|}
\hline \multirow[t]{2}{*}{ Compd. } & \multicolumn{5}{|c|}{ Gram-positive } & \multicolumn{3}{|c|}{ Gram-negative } \\
\hline & A. $n a$ & A. $v i$ & S. $m u$ & S. $s a$ & S. so & A. $a c$ & F. $n u$ & P. $g i$ \\
\hline 1 & 250 & 125 & 125 & 125 & 250 & 62.5 & 31.25 & 125 \\
\hline 2 & 7.8 & 7.8 & 3.9 & 15.6 & 62.5 & 3.9 & 3.9 & 7.8 \\
\hline 3 & 1.95 & 3.9 & 15.6 & 7.8 & 7.8 & 62.5 & $>250$ & 1.95 \\
\hline 4 & 31.25 & 7.8 & 62.5 & 31.25 & 62.5 & 15.6 & 7.8 & 3.9 \\
\hline 5 & 62.5 & 62.5 & 62.5 & 62.5 & 125 & 62.5 & 31.25 & 31.25 \\
\hline 6 & 125 & 125 & 125 & 125 & 125 & 31.25 & 15.6 & 62.5 \\
\hline 7 & 250 & 250 & 250 & 250 & 250 & 15.6 & 31.25 & 31.25 \\
\hline 8 & 62.5 & 31.25 & 250 & 62.5 & 125 & 250 & 31.25 & 31.25 \\
\hline 9 & $>250$ & 250 & $>250$ & 62.5 & 125 & 31.25 & 15.6 & 7.8 \\
\hline 10 & 125 & 31.25 & 62.5 & 62.5 & 125 & 15.6 & 7.8 & 7.8 \\
\hline 11 & 62.5 & 31.25 & 62.5 & 62.5 & 62.5 & 62.5 & 15.6 & 15.6 \\
\hline 12 & 125 & 125 & 62.5 & 62.5 & 125 & $>250$ & 250 & 250 \\
\hline Triclosan & 3.9 & 3.9 & 3.9 & 7.8 & 3.9 & 1.95 & 7.8 & 7.8 \\
\hline
\end{tabular}

A. na, Actinomyces naeslundii ATCC 12104; A. vi, Actinomyces viscosus ATCC 27044; S. mu, Streptococcus mutans ATCC 25175; S. sa, Streptococcus sanguinis ATCC 10556; S. so, Streptococcus sorbrinus ATCC6715; A. ac, Aggregatibacter actinomycetemcomitans ATCC 43717; F. nu, Fusobacterium nucleatum ATCC 10953; P. gi: Porphyromonas gingivalis ATCC 33277 
for two times. The combined extract was solved in water and partitioned with petroleum ether (PE), EtOAc and $n$-butanol, successively. Based on the preliminary bioassay, the EtOAc part showed the highest anti-oral microbial activity, and was thus applied for the following investigation. The EtOAc part was separated by silica gel $\mathrm{CC}$ using $\mathrm{CHCl}_{3}-\mathrm{MeOH}$ gradient (from 9:1 to 5:5) to yield six fractions, Frs. A-F. Fr. D was fractionated by MPLC system on a MCI gel CHP20P column with $\mathrm{MeOH}-\mathrm{H}_{2} \mathrm{O}$ system (5:95, 10:90, 30:70, 50:50 and 0:100) as the mobile phase to provide five fractions, Frs. D-1 to D-5. Fr. D-3 was subjected to Si CC and eluted with $\mathrm{CHCl}_{3}-\mathrm{MeOH}-\mathrm{H}_{2} \mathrm{O}$ system $(9: 1: 0.1)$ to generate three fractions, Fr. D-3-1 to D-3-3. Fr. D-3-2 was purified by repeated silica gel and Sephadex LH-20 CC to give compounds 5 $(8 \mathrm{mg}), \mathbf{6}(11 \mathrm{mg})$ and $\mathbf{1 1}(18 \mathrm{mg})$. Fr. D-3-3 was purified by HPLC to yield compounds $\mathbf{7}(5 \mathrm{mg}), \mathbf{9}(7 \mathrm{mg}), \mathbf{1 0}(3 \mathrm{mg})$ and $12(4 \mathrm{mg})$. Fr. D-4 was loaded on Si CC and eluted with $\mathrm{CHCl}_{3}-\mathrm{MeOH}-\mathrm{H}_{2} \mathrm{O}$ system $(85: 15: 1.5)$ to provide three fractions, Frs. D-4-1 to D-4-3. Compounds 2 (5 mg), $4(3 \mathrm{mg})$ and $8(9 \mathrm{mg})$ was obtained from Fr. D-4-1 after HPLC purification. Fr. D-4-2 was separated by HPLC to generated compounds $\mathbf{1}(5 \mathrm{mg})$ and $\mathbf{3}(6 \mathrm{mg})$.

\subsubsection{Spectroscopic Data of Bropapyriferol (1)}

Colorless gum, $\mathrm{C}_{25} \mathrm{H}_{30} \mathrm{O}_{6},[\alpha] 22_{\mathrm{D}}+27.6^{\circ}$ (c 0.16 , $\left.\mathrm{CHCl}_{3}-\mathrm{MeOH}, 1: 1\right) ; \mathrm{UV}\left(\mathrm{CHCl}_{3}-\mathrm{MeOH}\right) \lambda_{\max }(\log \varepsilon) 236$ (4.01) and $284(3.69) \mathrm{nm}$; IR (KBr) $\nu_{\max } 3419,2928,1623$, 1600, 1509, 1463, 1377, 1307, 1226, 1155, 1114, 1055, $999 \mathrm{~cm}^{-1}$; ${ }^{1} \mathrm{H}$ and ${ }^{13} \mathrm{C}$ NMR data see Table 1; EIMS $\mathrm{m} / \mathrm{z}$ $426[\mathrm{M}]^{+}$(1), 390 (6), 350 (20), 294 (9), 227 (14), 214 (14), 185 (29), 171 (11), 123 (100); (+) HRESIMS m/z 449.1954 (calcd. for $\mathrm{C}_{25} \mathrm{H}_{30} \mathrm{O}_{6} \mathrm{Na}, 449.1940$ ).

\subsection{Anti-oral Microbial Test}

Microorganisms including Gram-positive [Actinomyces naeslundii (ATCC 12104), Actinomyces viscosus (ATCC 27044), Streptococcus mutans (ATCC 25175), Streptococcus sanguinis (ATCC 10556) and Streptococcus sorbrinus (ATCC6715)] and Gram-negative [Aggregatibacter actinomycetemcomitans (ATCC 43717), Fusobacterium nucleatum (ATCC 10953) and Porphyromonas gingivalis (ATCC 33277)] bacteria were used for anti-oral microbial test. All bacterial strains were obtained from the American Type Culture Collection (ATCC). A broth microdilution method was used to assess the anti-bacterial activity of the fractions and isolates by determining the minimum inhibitory concentration (MIC) [22]. In brief, a serial doubling dilution of each sample in the range $0.12-250 \mathrm{ppm}$ was prepared in a 96-well plate. $100 \mu \mathrm{L}$ of bacterial suspension was added into the 96-well plate, and the final concentration in each well was adjusted to $5 \times 10^{7} \mathrm{CFU} / \mathrm{mL}$. After incubated aerobically or anaerobically at $37^{\circ} \mathrm{C}$ for about $20 \mathrm{~h}$, the plate was determined by a BioTek EL $\times 808$ Microplate Reader. The bacteria growth was indicated by the turbidity determined at $\mathrm{OD}_{630}$, which was performed in duplicate. The minimum inhibitory concentration (MIC) is defined as the lowest concentration of the sample at which the microorganism tested does not demonstrate visible growth. Triclosan (Purity $>99 \%$, Ciba Specialty Chemicals) was used as the positive control.

\subsection{Quantum Computation}

The ${ }^{13} \mathrm{C}$ NMR and $[\alpha]_{\mathrm{D}}$ calculations for compound $\mathbf{1}$ were carried out using Gaussian 09 program. Conformational search was achieved by Spartan '14 in MMFF94 s force field, and the lowest conformer was further optimized with the $\mathrm{hf} / 3-21 \mathrm{~g}$ and DFT b3lyp/6-311+g(d,p) methods in Gaussian 09 program package. ${ }^{13} \mathrm{C}$ NMR shielding constants were calculated with the GIAO method at b3lyp/6$311+\mathrm{g}(\mathrm{d}, 2 \mathrm{p})$ level in pyridine with PCM, which were converted into chemical shifts by referencing to TMS. $[\alpha]_{D}$ values were calculated at b3lyp/6-31 g(d,p) level based on the above DFT optimized geometries.

Acknowledgements This work was financially supported by the Program of Yunling Scholarship, the CAS "Light of West China" Program (Western Youth Scholars "A"), the Youth Innovation Promotion Association CAS (2013252), and the Applied Basic Research Programs of Yunnan Province (2017FB137).

\section{Compliance with Ethical Standards}

Conflict of interest These authors have no conflict of interest to declare.

Open Access This article is distributed under the terms of the Creative Commons Attribution 4.0 International License (http://creativeco mmons.org/licenses/by/4.0/), which permits unrestricted use, distribution, and reproduction in any medium, provided you give appropriate credit to the original author(s) and the source, provide a link to the Creative Commons license, and indicate if changes were made.

\section{References}

1. J. González-Lorca, A. Rivera-Hutinel, X. Moncada, S. Lobos, D. Seelenfreund, A. Seelenfreund, N. Z. J. Bot. 53, 75-89 (2015)

2. R.H. Ji, X.F. Lin, W.B. Zhang, S.L. Bai, China For. Prod. Ind. 44, 3-6 (2017)

3. Y. Ding, J. Qiu, X.Y. Liu, Nat. Prod. Res. Dev. 26(1327-1331), 1337 (2014)

4. H.W. Ryu, B.W. Lee, M.J. Curtis-Long, S. Jung, Y.B. Ryu, W.S. Lee, K.H. Park, J. Agric. Food Chem. 58, 202-208 (2010)

5. H.H. Ko, W.L. Chang, T.M. Lu, J. Nat. Prod. 71, 1930-1933 (2008) 
6. S.C. Fang, B.J. Shieh, R.R. Wu, C.N. Lin, Phytochemistry 38, 535-537 (1995)

7. D. Lee, K.P.L. Bhat, H.H.S. Fong, N.R. Farnsworth, J.M. Pezzuto, A.D. Kinghorn, J. Nat. Prod. 64, 1286-1293 (2001)

8. H.W. Ryu, M.J. Curtis-Long, S. Jung, Y. Jeong, D.S. Kim, K.Y. Kang, K.H. Park, Food Chem. 132, 1244-1250 (2012)

9. Z.M. Li, J.J. Chen, M.H. Yan, Med. Plant 1, 33-35 (2010)

10. Q. Sun, F.F. Li, D. Wang, J. Wu, G.D. Yao, X. Li, L.Z. Li, Q.B. Liu, X.X. Huang, S.J. Song, RSC Adv. 6, 55919-55929 (2016)

11. J. Kwon, N.T. Hiep, D.W. Kim, S. Hong, Y. Guo, B.Y. Hwang, H.J. Lee, W. Mar, D. Lee, J. Nat. Prod. 79, 1938-1951 (2016)

12. L. Cui, H.S. Lee, D.T. Ndinteh, J.T. Mbafor, Y.H. Kim, T.V.T. Le, P.H. Nguyen, W.K. Oh, Planta Med. 76, 713-718 (2010)

13. F.J. Guo, L. Feng, C. Huang, H.X. Ding, X.T. Zhang, Z.Y. Wang, Y.M. Li, Phytochemistry Lett. 6, 331-336 (2013)

14. J. Matsumoto, T. Fujimoto, C. Takino, M. Saitoh, Y. Hano, T. Fukai, T. Nomura, Chem. Pharm. Bull. 33, 3250-3256 (2008)
15. T. Mitsuo, A. Masaki, M. Tadashi, S. Akira, T. Kokichi, Chem. Lett. 3, 339-340 (1980)

16. Z.Q. Yin, J.F. Chao, L.H. Zhang, W.C. Ye, W.B. Shen, S.X. Zhao, Nat. Prod. Res. Dev. 18(420-422), 425 (2006)

17. S.S. Jia, C.M. Ma, J.M. Wang, Acta Pharm. Sin. 25, 758-762 (1990)

18. S.C. Fang, B.J. Shieh, C.N. Lin, Phytochemistry 37, 851-853 (1994)

19. S.S. Jia, D. Liu, X.P. Zheng, Y. Zhang, Y.K. Li, Acta Pharm. Sin. 28, 28-31 (1993)

20. F. Machumi, G. Bojase-Moleta, R. Mapitse, I. Masesane, R.R.T. Majinda, Nat. Prod. Comm. 1, 287-292 (2006)

21. L.S. Ding, Q.L. Liang, Y.F. Teng, Acta Pharm. Sin. 32, 600-602 (1997)

22. J.F. Liu, Z.Y. Jiang, C.A. Geng, X.B. Zou, Y. Shi, Y.B. Ma, X.M. Zhang, J.J. Chen, Planta Med. 76, 1464-1467 (2010) 